American Journal of Applied Sciences 4 (9): 700-708, 2007

ISSN 1546-9239

(C) Science Publications 2007

\title{
Analysis Heat Flow Between Seat and Valve of ICE
}

\author{
${ }^{1}$ M. H. Shojaefard, ${ }^{1}$ A. R. Noorpoor, ${ }^{2}$ M. Ghaffarpour, ${ }^{1}$ F. Mohammadi \\ ${ }^{1}$ Automotive Engineering Department, Iran University of Science and Technology, Tehran, Iran \\ ${ }^{2}$ Department of Mechanical Engineering, University of Illinois at Chicago, 842 Taylor Street, 2039 ERF \\ (MC251), Chicago, Illinois 60607
}

\begin{abstract}
An interesting application of system identification method is to investigate the heat transfer from the exhaust valve, especially the valve burning at high temperatures. This study consists of experimental and analytical works. For the experiment, two co-axial rods were used to transfer heat constantly at their contact surfaces. Using the measured temperatures at different locations of the rods and the analytical method, the temperatures distribution of the rods were calculated; consequently the heat transfer coefficient at contact surface was calculated. By applying the system identification method and having the temperatures at both sides of the contact surface, the temperature transfer function was calculated. The transfer function is changed as the operating conditions are varied. Using the calculated transfer function and the system identification method, a computational model was created. By knowing the temperature of one rod, the temperature of the other rod was estimated with high accuracy.
\end{abstract}

Key words: System identification, exhaust valve, heat transfer coefficient

\section{INTRODUCTION}

The heat is transferred from the exhaust valve to its seat as they come into contact with each other during the opening and closing of the exhaust valve to avoid any damage to the engine. Note that the exhaust valve temperature distribution has significant effect on engine performance. Therefore, substantial theoretical and experimental effort continues for the measurement and prediction of periodic contact conductance ${ }^{[1-4]}$. The available information includes data on thermal and mechanical properties. From this information, one can estimate the thermal resistance of the interface surfaces at permanent contact ${ }^{[5-10]}$. The objective of these studies was to estimate the average thermal resistance of the surfaces. Examples include heat transfer between a valve and seat in an internal combustion engine, a soldering iron and work piece on an assembly line, and a hot work-piece and die under repetitive forming conditions.

The engine control unit monitors the coolant temperature, engine load, throttle position, engine speed and knock sensor to regulate the fuel, spark, and cooling processes. To increase the engine's thermal efficiency, the ECU requires a model that estimates the thermal behavior of the engine cylinder components. The ultimate goal for the researchers is to create a model with higher operating temperatures within the cylinder without damaging any components. Therefore, a mathematical model is necessary to describe the thermal behavior of the exhaust valve with attention focused on periodic contact resistance, for example see reference ${ }^{[11]}$.

Howard and Sutton ${ }^{[12]}$, Reed and Mullineux ${ }^{[13]}$, and Mikhailov ${ }^{[14]}$ analytically examined the problem of the quasi-steady-state heat transfer across two surfaces coming into regular, periodic contact under the assumption of prefect thermal contact at the interface. Vick and Ozisik ${ }^{[15]}$ extended the analysis to include the effects of thermal contact interface. In another work by Howard $^{[16]}$, similar to his previous work $^{[12]}$, he concluded that the earlier theoretical work could predict the average contact resistance due to periodic heat flow at the surfaces. Later, Flach and Ozisik ${ }^{[17]}$ employed the inverse heat conduction method for predicting timedependent thermal contact conductance from temperature measurements taken within the mediums. Moses and Johnson ${ }^{[18]}$ studied an identical materials and for the case of low constant pressure and moderate temperature. They concluded the thermal contact resistance is not constant.

Note that at the contact surfaces, the heat transfer is restricted since heat is constrained to pass primarily through narrow bridges. This is due to the surface irregularities. This limitation causes significant changes in temperature distribution across the interface of the

Corresponding Author: Dr. M. Ghaffarpour, Department of Mechanical, Engineering, University of Illinois at Chicago, 842 Taylor Street, 2039 ERF (MC 251), Chicago, Illinois 60607 
two surfaces. Although considerable progress has been made towards estimating the exhaust valve temperature, we are still far from a coherent and calculating accurate temperature distribution of the exhaust valve. Note that all researchers have investigated this study using two coaxial rods and a different method than the system identification method. Here, the acquired results are extremely useful as a baseline to investigate the contact surface problem in a complex exhaust valve of internal combustion engines due to the following:

* In IC engines, the exhaust valve is in contact with the seat approximately $3 / 4$ of the engine cycle.

* In surface contact problem, two rods can simulate the exhaust valve and its seat if the dynamical behavior is simulated. The in-house designed apparatus has the capability of simulating the valve motion mechanism (even for variable frequency). For this reason, an electro-motor gearbox 24V-DC with maximum speed 2000rpm and maximum power $250 \mathrm{~W}$ has been used.

* The main challenge in the measurement of the interface temperature and the calculation of heat transfer from valve into the seat is that installation of the thermocouple is very difficult at the interface near the valve. Due to high temperature of the valve and high motion strong noise is produced. In this case, the System Identification Method was found to be the best method to satisfy the objective of the work.

\section{THEORY AND FORMULATION}

The purpose of this study is to estimate the temperatures at contact surface of two rods using the system identification method; to calculate the heat transfer at contact surface in transient process. Also, the temperature transfer function is calculated. In this case, the heat flux is known at the boundary. The ultimate goal and the extension of this work are to apply these results to internal combustion engines. The measurement and estimation of the exhaust valve temperature is extremely difficult in internal combustion engines. By calculating transfer function using the system identification method, a computational model can be created. By applying the exhaust valve seat temperature as input, the exhaust valve temperature can be estimated as output with high accuracy.

To accomplish this, an experimental apparatus was designed and developed to achieve the objective. To model the surface temperature and heat flux values accurately, the spatial measurements must be close to the contact surfaces since the transient effects are not accounted for by the extrapolation method. The minimum distance between temperature sensor and the contact surface is limited by manufacturing limitations. Also, care must be taken not to disturb the surface characteristics by installing the sensor too close to the surface. Due to rapid and significant number of contacts, the temperature sensor cannot be mounted close to the contact surfaces. Therefore, an improved method to estimate the instantaneous contact conductance is needed to detect fast periodic variations at the contact surface conditions.

There are two methods to approach: (1) solve directly the coupled, two-region inverse heat conduction problem for contact conductance or (2) decouple the regions and solve for the surface temperature and heat flux in each region irrespective of the other. The second approach would be significantly more accurate when applied to constant thermophysical property regions. This method yields two linear estimation problems, which easily can be solved without iterations. Also, a computationally efficient analytical solution is available for evaluating the direct solution.

The analytical approach to solve the problem for each of the long rods as shown in Fig. 1 is defined as:

$$
\begin{aligned}
& \mathrm{T}_{\mathrm{xx}}=(1 / \alpha) \mathrm{T}_{\mathrm{t}} ; \quad\left(\partial^{2} \mathrm{~T}(\mathrm{x}, \mathrm{t}) / \partial \mathrm{x}^{2}\right)=(1 / \alpha)(\partial \mathrm{T}(\mathrm{x}, \mathrm{t}) / \partial \mathrm{t}) \\
& \text { in } 0<\mathrm{x}<\mathrm{L} \text { and } \mathrm{t}>0 \\
& L=\Delta x \quad ; \quad \text { B.C.: }\left\{\begin{array}{l}
T(0, t)=f_{1}(t) \\
T(L, t)=f_{2}(t)
\end{array} ; \text { I.C.: } T(x, 0)=f(x)\right.
\end{aligned}
$$

Note that $\mathrm{T}_{\mathrm{C} 1}$ and $\mathrm{T}_{\mathrm{C} 2}$ are the estimated temperatures in Fig. 1. The length/diameter of the experimental rod was very large and it was perfectly insulated. Therefore, the heat transfer through the rod can be assumed to be one-dimensional using rectangular coordinate.

In Eq. (2), since the boundary conditions are timedependent, the problem is non-homogeneous. Splitting the problem into several simpler problems can often solve complicated non-homogeneous problems.

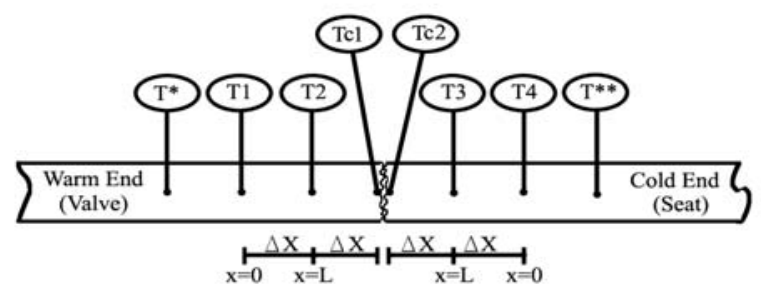

Fig. 1: Thermocouples arrangement of the rods

Solving for $\mathrm{T}(\mathrm{x}, \mathrm{t})$ using Eigen function method yields the following:

$$
\begin{aligned}
& T(x, t)=f_{1}(t)+\frac{x}{L}\left[f_{2}(t)-f_{1}(t)\right]+\sum_{n=1}^{\infty} a_{n}(t) \quad \operatorname{Sin}\left(\frac{n \pi}{L}\right) x \\
& \text { For first rod: } \\
& \left\{\begin{array}{l}
f_{1}(t)=T_{1}(t) \\
f_{2}(t)=T_{2}(t)
\end{array} ; \quad f(x)=T_{\mathrm{inf}} ; \quad i=1\right.
\end{aligned}
$$

And for second rod: 
$\left\{\begin{array}{l}f_{1}(t)=T_{4}(t) \\ f_{2}(t)=T_{3}(t)\end{array} \quad ; \quad f(x)=T_{\text {inf }} ; \quad i=2\right.$

Eq. (3) is one-dimensional temperature distribution of each rod for transient problems with time-dependent boundary conditions that are measured at each instance using the installed sensors at $x=0$ and $x=L$. The temperature at the end of each rod at contact surfaces, $T_{c 1}$ and $T_{c 2}$ can analytically be calculated using Eq. (6). It is calculated by Mack Loren expansion at $x=L$.

$$
\begin{aligned}
T_{C i}(x, t) & =f_{2}(t)+\left.\frac{\partial T}{\partial x}\right|_{L}(x-L) \\
+ & \left.\frac{1}{2 !} \frac{\partial^{2} T}{\partial x^{2}}\right|_{L}(x-L)^{2}+\left.\frac{1}{3 !} \frac{\partial^{3} T}{\partial x^{3}}\right|_{L}(x-L)^{3}
\end{aligned}
$$

\section{MATERIALS AND METHODS}

The experimental apparatus shown in Fig. 2 consists of two rods with one of the non-contacting ends held at a fixed temperature controlled by an icewater reservoir. The other non-contacting ends held at constant heat flux using an electrical heater. The two rods are suspended by a spring and are free to slide along the two Teflon sleeves to reduce friction and binding at the sliding contact. The Teflon is cut to allow thermocouple to access and move freely in a vertical direction as the surfaces come into and move out of contact. The adjacent ends are brought into contact and are separated cyclically. This consists of a camshaft capable to change various rotational velocities by a selectable speed DC electro-motor, which is located above the upper rod. The schematic diagram of the apparatus is shown in Fig. 3. This figure shows the positions of six thermocouples, which two of them are for calibration of the test rig.

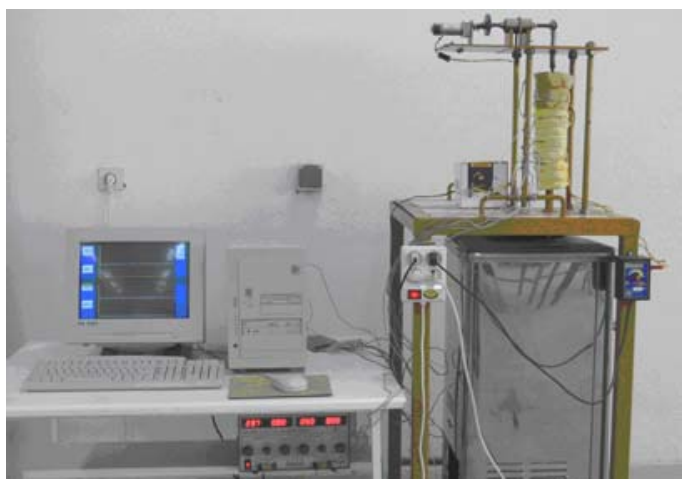

Fig. 2: General view of the experimental setup

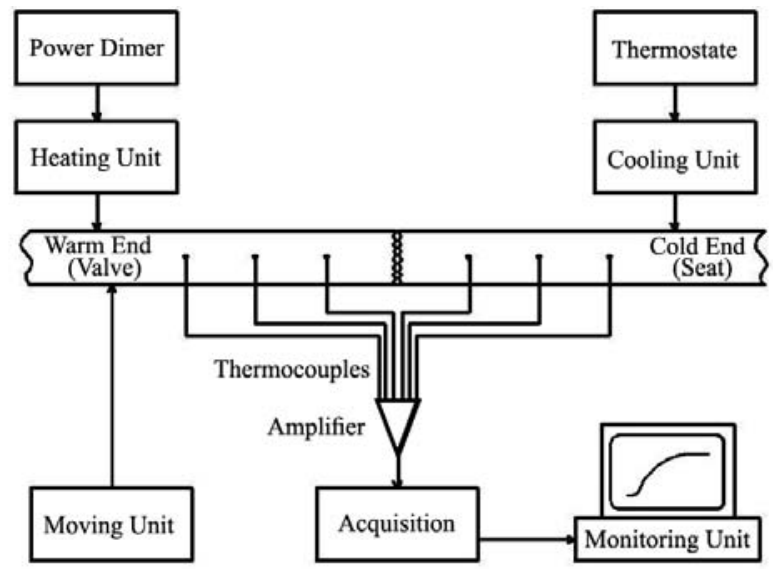

Fig. 3: Experimental setup Diagram

The contact faces are free of coatings or surface oxidation. Three chromel-alumel K-type thermocouples are installed on the centerline of each rod at $0.02 \mathrm{~m}$ intervals. When the experiment is started, a transient heat flux passes through the test specimens across the interface. During the experiment, first, we used Dimmer Device to control the inlet of the electrical heater. But some jumps were observed in the curves.

It was believed that the jumps in the curves were due to the noise, which was deleted from the original curves. Then, the Auto-Transe device was used instead of the Dimmer. In this case, no jump was observed in the curves. Consequently, the signals shown in the paper are the exact acquired data. Therefore, in our current results, no noise was eliminated from the signals. The generated noises in the experiment are due to environment factors and apparatus, such as thermocouples, A/D board, electrical current, etc.

The digital data acquisition system include an Intel PC/Pentium II computer, a monolithic thermocouple amplifier with cold junction compensation (AD594A with four terminals), a single DC power supply, and four chromel-alumel type $\mathrm{k}$ thermocouples made from $0.122 \mathrm{~mm}$ diameter wire. These thermocouples were selected because the range of the measurement of the $\mathrm{K}$-Type thermocouple is wider and the percentage of its error is less than the others such as T-Type thermocouple. AD594A board can amplify $10 \mathrm{mVolt}$ analog signals up to +5 to \pm 15 Volts and multiplex 6 differential analog input signals to one $\mathrm{A} / \mathrm{D}$ input channel. The data-sampling program was written using Borland $\mathrm{C}$ programming language on the windows platform. The $\mathrm{A} / \mathrm{D}$ device used in this test recorded 3 temperatures per second. The energy transfer through the rods is assumed to be one-dimensional by neglecting the transverse heat transfer and perfect 
insulation of the rods. For this experiment, the rods were held together under constant pressure. For Each rod two thermocouples are used for the analysis and one to study the effectiveness of the calibration and insulation of the experimental setup. A separate set of experiments was conducted to check the presence of radial temperature gradients in the rods. Note that the experimental results confirmed the validity of the assumption.

In one-dimensional steady state condition, if the variation of the temperature and the transverse heat transfer are insignificant, the heat flux is a function of the material property and the distance between two points of the rod. According to Eq. (7), the temperature difference for these two points is:

$\Delta T(x, t)=q \Delta x /(K)$

To study the above relationship, three thermocouples are installed on each rod as shown in Fig. 1. The steady state temperatures are recorded in Table 1 . The temperature difference between each two adjacent point is within $1 \%$. Therefore, it confirms the one-dimensionality of the heat transfer. For every 20 recorded data, one was selected for analysis as is shown in Fig. 4.

Table 1: Recorded steady state temperatures and temperature difference between adjacent points on the rods

\begin{tabular}{|c|c|c|c|c|c|}
\hline $\mathrm{T} *(\mathrm{c})$ & $\mathrm{T} 1(\mathrm{c})$ & $\mathrm{T} 2(\mathrm{c})$ & $\mathrm{T} 3(\mathrm{c})$ & $\mathrm{T} 4(\mathrm{c})$ & $\mathrm{T}^{* *}(\mathrm{c})$ \\
\hline 222.7 & 195.3 & 167.8 & 95.2 & 64.4 & 33.3 \\
\hline $\mathrm{d} 1=\left(\mathrm{T}^{*}-\mathrm{T} 1\right)$ & \multicolumn{2}{|c|}{$\mathrm{d} 2=(\mathrm{T} 1-\mathrm{T} 2)$} & $\mathrm{d} 3=(\mathrm{T} 3-\mathrm{T} 4)$ & \multicolumn{2}{|c|}{$\mathrm{d} 4=\left(\mathrm{T} 4-\mathrm{T}^{* *}\right)$} \\
\hline 27.4 & \multicolumn{2}{|c|}{27.5} & 30.8 & & 31.1 \\
\hline \multicolumn{3}{|c|}{$d 1-d 2$} & \multicolumn{3}{|c|}{$d 3-d 4$} \\
\hline \multicolumn{3}{|c|}{$d 1$} & \multicolumn{3}{|c|}{$\overline{d 3}$} \\
\hline & $0.4(\mathrm{C})$ & & \multicolumn{3}{|c|}{$1.0(\mathrm{C})$} \\
\hline
\end{tabular}

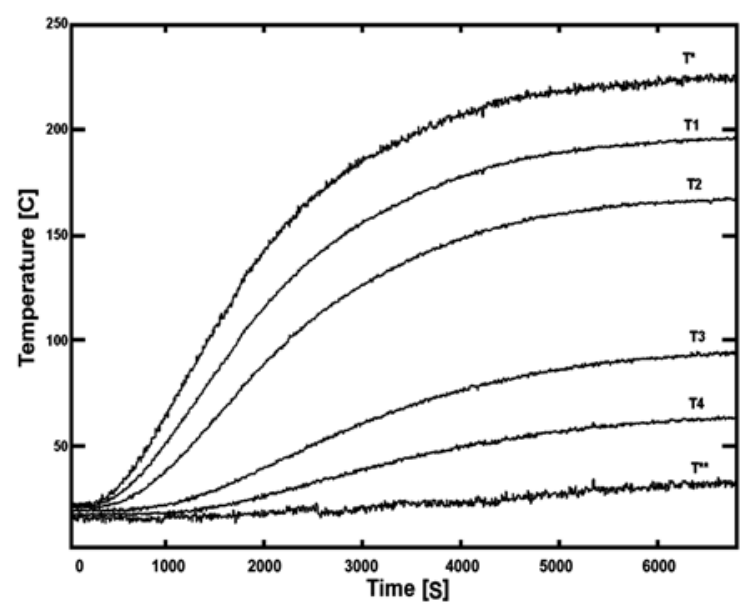

Fig. 4: Temperature data used for calibration corresponding to Fig. 1

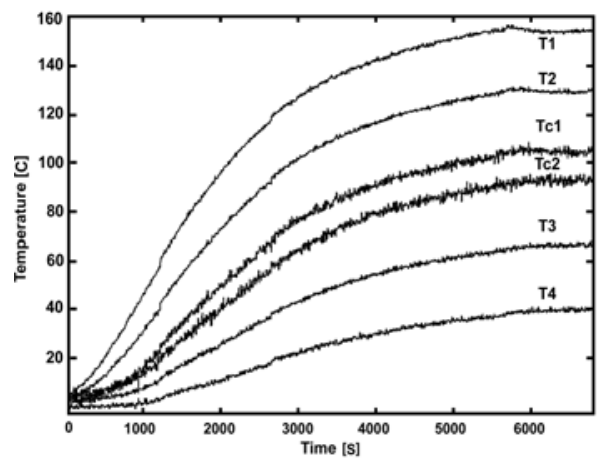

Fig. 5: Temperatures close to contact surface for $\mathrm{q}_{1}=70 \mathrm{Kw} / \mathrm{m}^{2}$ corresponding to Fig. 4.

In this transient heat transfer, at the start of experiment $(\mathrm{t}=0)$ the hot rod is heated by an electrical heater (installed at the end of warm rod); then, the cold rod starting to warm up by the hot rod until it reaches steady state condition. Note that this work is not a periodic contact problem. Therefore, the contact interval is the duration of the experiment.

Two experiments were conducted at different operating conditions, various heat flux, initial, and boundary conditions. To determine the temperature at the adjacent contacting surface, temperature distribution is calculated using Eq. (6) from the measured data (Fig. 5 and 6). They show a temperature drop across the contact interface (temperature difference between $T_{C 1}$ and $T_{C 2}$ ) due to the contact resistance. The heat fluxes values are 70 and $95 \mathrm{Kw} / \mathrm{m}^{2}$ as are shown in the caption of the figures 5 and 6 . The mean interface pressure was approximately equal to the valve and seat interface pressure of the investigated engine, which is about $20 \mathrm{Kpa}$. The pressure is constant during the experiment. Note that the transfer function can be identified to predict this contact resistance using system identification method.

\section{IDENTIFICATION}

Concept: System Identification method allows building mathematical models of dynamic systems based on measured data. This is accomplished by adjusting parameters within a given model until the result matches relatively well with the measured data. Model validation can be carried out by using a separate set of data, which differs from estimating data, to evaluate the model's properties and for validation purposes. The procedure to model a dynamical system is shown in flowchart 1. 


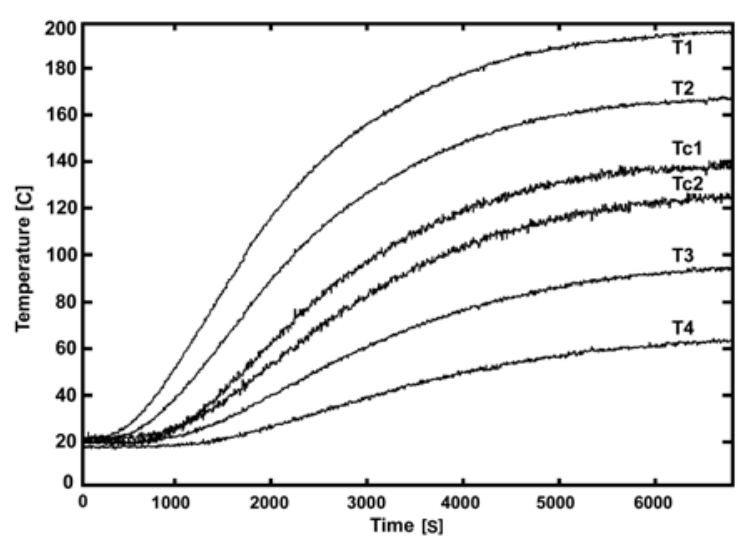

Fig. 6: Temperatures close to contact surface for $\mathrm{q}_{2}=95 \mathrm{Kw} / \mathrm{m}^{2}$ corresponding to Fig. 4 .

The techniques are applied to general models. The auto regressive (ARX) and the auto regressive moving average (ARMAX) models are based on different equations and all types of linear state-space models. For parametric models, the model structure should be specified. If inputs, outputs, and disturbances are $u, y$, and e, respectively, their relationship can be depicted as,

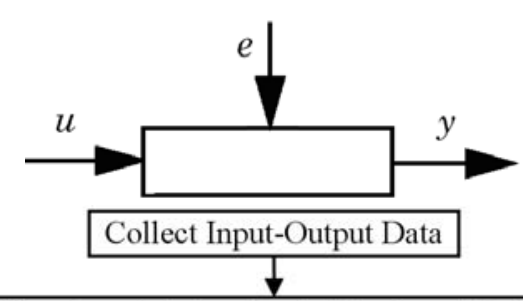

Remove Trends and Select Useful Portion of Original Data

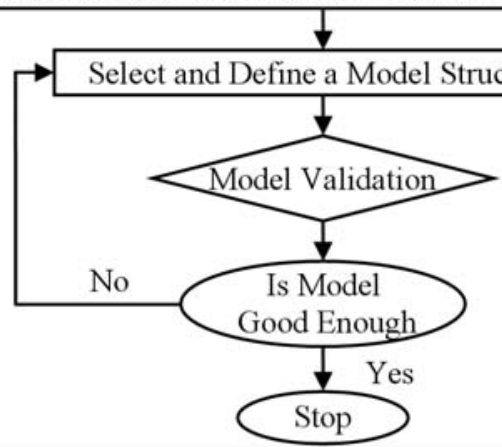

Flowchart 1: System identification flowchart

Note that the disturbance may be due to corrupted input-output data and normally is entirely unpredictable. They are swept sine and white noise. Note that the white noise is a combination of different frequencies.

Assuming unit-sampling interval, the input signal is $u(t)$ ' and output signal is $y(t)$ for: $t=1,2, \ldots, N$
If the signals are related by a linear system, $y(t)=G(q) u(t)+v(t)$

Where $\mathrm{q}$ is the shift operator and $G(q)$, is called the transfer function and $v(t)$ is an additional, nonmeasurable noise that can be described as filtered white noise:

$v(t)=H(q) e(t)$

$\mathrm{G}$ and $\mathrm{H}$ in Eq. (8), which are in terms of frequency $(\omega)$, is described as rational functions of $q^{-1}$ and specify the numerator and denominator coefficients.

A commonly used parametric and simple model is ARX that corresponds to:

$G(q)=\left(q^{-n k}\right)(B(q) / A(q)) ; \quad H(q)=1 / A(q)$

Where $\mathrm{B}$ and $\mathrm{A}$ are polynomials in the delay operator $q^{-1}$ :

$$
\begin{aligned}
& A(q)=1+a_{1} q^{-1}+a_{2} q^{-2}+\ldots+a_{n_{a}} q^{-n_{a}} \\
& B(q)=b_{1}+b_{2} q^{-1}+\ldots+b_{n_{b}} q^{-\left(n_{b}-1\right)}
\end{aligned}
$$

Here, the numbers $n_{a}$ and $n_{b}$ are the orders of $A(q)$ and $B(q)$, respectively. The number $n_{k}$ is the number of delays from input to output. Note that for any identification problem, there are several methods to approach the problem. In some of them, the objective functional needs always to be in the analysis. In this paper, we used the so-called black-box method to identify the transfer function.

In this method the input and output are known by experimental and computational solutions and the objective functional does not needs to be in the analysis.

Parametric Model Structure: The general form of common black-box parametric model structure is:

$$
\begin{aligned}
\mathrm{A}(\mathrm{q}) \mathrm{y}(\mathrm{t})=(\mathrm{B}(\mathrm{q}) / \mathrm{F}(\mathrm{q})) \mathrm{u}\left(\mathrm{t}-\mathrm{n}_{\mathrm{k}}\right) \\
+(\mathrm{C}(\mathrm{q}) / \mathrm{D}(\mathrm{q})) \mathrm{e}(\mathrm{t})
\end{aligned}
$$

The model structures are linear difference equations, which relate the current output $y(t)$ to a finite number of previous outputs $\mathrm{y}(\mathrm{t}-\mathrm{k})$ and

\begin{tabular}{|c|c|c|c|c|c|c|c|c|}
\hline Model & $\frac{1}{7}$ & $\mid \begin{array}{l}\vec{x} \\
\vec{x}\end{array}$ & $\frac{2}{2}$ & 党 & 忿 & 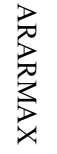 & 雨 & 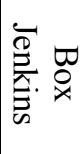 \\
\hline $\begin{array}{c}\text { Used } \\
\text { Polynomial }\end{array}$ & $\varpi$ & $\mathbb{Z}$ & $\underset{\sim}{\vec{D}}$ & ฉ & $\underset{\theta}{\otimes}$ & $\begin{array}{l}\vec{U} \\
\stackrel{\vec{\theta}}{ }\end{array}$ & $\mathbb{T}_{1}^{\square}$ & $\begin{array}{l}\stackrel{\varpi}{11} \\
\Theta\end{array}$ \\
\hline
\end{tabular}
inputs $u(t-k)$. Depend on polynomials used in Eq. (12), several model structures can be selected. Table 2 shows the polynomials for each model. 
Am. J. Applied Sci. 4 (9): 700-708, 2007

Structure of State-Space Model: The basic StateSpace model can be written as:

$x(t+1)=A x(t)+B u(t)+K e(t)$

$y(t)=C x(t)+D u(t)+e(t)$

This is equivalent to Eq. (8), which $G(q)$ and $H(q)$ are given by Eq. (14) and Eq. (15).

$$
\begin{aligned}
& G(q)=C\left(q I_{n x}-A\right)^{-1} B+D \\
& H(q)=C\left(q I_{n x}-A\right)^{-1} K+I_{n y}
\end{aligned}
$$

Here $I_{n x}$ is the $n_{\mathrm{x}}$ by $n_{\mathrm{x}}$ identity matrix and $n_{y}$ is the dimension of $y(t)$ and $e(t)$. The most important structure index is the model order; i.e., the dimension of the state vector $x$. Assigning $K$ to zero gives an OutputError method; i.e., the difference between the models' simulated output and the measured data is minimized.

Validation: Table 3 and Table 4 show the model order, FPE, loss function, and percentage of the difference of the model structures and measured data. The most important structure index is the model order. The numbers $n_{a}, n_{b}, n_{f}, n_{c}, n_{d}$ are the orders of $A(q)$, $B(q), F(q), C(q)$, and $D(q)$ polynomials in general form of the parametric model structure (Eq.(12)), respectively. The number $n_{k}$ is the number of delays from input to output.

Loss function is the value of the identification criterion for estimation purposes. It is equal to the determinant of the covariance matrix of the prediction errors, i.e., the determinant of noise variance. Another computing model selection criterion is FPE. In this study minimum difference of measured and estimated data is used for choosing the model structure.

\begin{tabular}{|c|c|c|c|c|c|}
\hline $\begin{array}{l}\text { Parametric } \\
\text { model }\end{array}$ & ARMAX & BJ & $\mathrm{OE}$ & $\begin{array}{l}\text { State Space } \\
\text { model }\end{array}$ & ARX \\
\hline$n_{a}$ & 2 & 0 & 0 & $\begin{array}{l}4 \text { state and } \\
4 \text { recursive }\end{array}$ & 10 \\
\hline$n_{b}$ & 2 & 2 & 2 & input, output & 10 \\
\hline$n_{f}$ & 0 & 2 & 2 & and noise & 0 \\
\hline$n_{c}^{J}$ & 2 & 2 & 0 & are used & 0 \\
\hline$n_{d}$ & 0 & 2 & 0 & utilizing & 0 \\
\hline$n_{k}$ & 1 & 1 & 1 & $\begin{array}{l}\text { N4SID } \\
\text { algorithm. }\end{array}$ & 1 \\
\hline FPE & 2.05 & 1.16 & 4.20 & 2.52 & 1.24 \\
\hline $\begin{array}{l}\text { Loss function } \\
\text { \%Difference }\end{array}$ & 2.03 & 1.13 & 4.17 & 2.47 & 1.20 \\
\hline $\begin{array}{l}\text { (Measured and } \\
\text { Model } \\
\text { Estimation data) }\end{array}$ & 4.9 & 5.2 & 6.8 & 9.1 & 11.4 \\
\hline
\end{tabular}

Table 3: Models properties and comparison of the measured and
Table 4: Comparison of the measured and estimated results for lower order models

\begin{tabular}{llllll}
\hline $\begin{array}{l}\text { Parametric } \\
\text { model }\end{array}$ & ARMAX & BJ & OE & $\begin{array}{l}\text { State Space } \\
\text { model }\end{array}$ & ARX \\
\hline FPE & 2.16 & 1.13 & 4.49 & 2.20 & 1.89 \\
$\begin{array}{l}\text { Loss function } \\
\text { \%Difference } \\
\text { (Measured and }\end{array}$ & 2.15 & 1.11 & 4.47 & 2.18 & 1.88 \\
$\begin{array}{l}\text { Model } \\
\text { Estimation data) }\end{array}$ & 7.2 & 4.2 & 7.4 & 11.7 & 7.4 \\
\hline
\end{tabular}

\section{RESULTS AND DISCUSSION}

Figure 5 and 6 show the measured temperatures of $\mathrm{T} 1$ and $\mathrm{T} 2$ at hot rod, where $\mathrm{T} 3$ and $\mathrm{T} 4$ at cold rod for two different heat fluxes. In these figures, $T_{C 1}$ and $T_{C 2}$ are the temperatures at the adjacent contact surfaces that are estimated using Eq. (6). The measured T1, T2, $\mathrm{T} 3$, and T4 show different values when the system is turned on. This is due to the fact that the end of the noncontacting part of the hot rod is at the ambient temperature. The end of non-contacting part of the cold rod is in the ice-water reservoir. This causes a small temperature difference between the two rods.

The heat transfer coefficient of the contact surface is shown in Fig. 7. The trends show decreasing the heat flux, temperature distribution, and the heat transfer coefficient $h_{c}(t)$ for the case of non-periodic contact. The results are similar to what was reported by other investigators ${ }^{[18]}$. The comparison of our results with reference ${ }^{[18]}$ is acceptable because part of their research was performed under quasi-steady condition.

When the system is started to acquired data, the heat transfer coefficient $h_{c}(t)$ is very low up to 1200 second. Then, it decreases slowly until it reaches steady state condition.

According to Table 3, the ARMAX model matches very well; but the ARX doesn't match very well with experimental data. The residual of ARMAX model is shown in Fig. 8. Finally, the ARMAX model is chosen as parametric model structure.

Since the data-sampling interval is constant, the case is time-invariable. The general form of discontinuous time-invariable single-input and singleoutput (SISO) system for the ARMAX model is: $A\left(z^{-1}\right) z(k)=B\left(z^{-1}\right) u(k)+C\left(z^{-1}\right) n(k)$

Where $u(k)$ and $z(k)$ represent the input variable and output signal, respectively. The $n(k)$ is the disturbance of the system. In discontinuous time cases, notation of shift operator $\mathrm{q}$, output $\mathrm{y}$, and noise $\mathrm{e}$ 
convert to $\mathrm{k}, \mathrm{z}$, and n. $A\left(z^{-1}\right), B\left(z^{-1}\right)$ and $C\left(z^{-1}\right)$ is described as:

$$
\begin{aligned}
& A\left(z^{-1}\right)=1+a_{1} z^{-1}+a_{2} z^{-2}+\ldots+a_{n a} z^{-n a} \\
& B\left(z^{-1}\right)=b_{1} z^{-1}+b_{2} z^{-2}+\ldots+b_{n b} z^{-n b} \\
& C\left(z^{-1}\right)=1+c_{1} z^{-1}+c_{2} z^{-2}+\ldots+c_{n c} z^{-n c}
\end{aligned}
$$

The input and output signals are temperature at adjacent contacting surfaces $\left(T_{C 1}\right.$ and $\left.T_{C 2}\right)$ :

$u(k)=T_{C 1}(K) ; z(k)=T_{C 2}(k) ; k=0,1,2, \ldots, N$

According to the definition of shift (time-delay) operator $z^{-1}$ :

$$
T_{C 2}(k) z^{-1}=T_{C 2}(k-1), T_{C 1}(k) z^{-1}=T_{C 1}(k-1)
$$

Here, the disturbance is white noise with variance of 1 and average of zero. Combination of Eq. (16) and Eq. (21) gives:

$$
T_{C 2}(k)=G\left(z^{-1}\right) \times T_{C 2}(k)+V(k)
$$

The estimated dynamic model of the system from the measured input and output data can be identified in the form of $\mathrm{Z}$ transfer function:

$$
G\left(z^{-1}\right)=\frac{B\left(z^{-1}\right)}{A\left(z^{-1}\right)}=\frac{b_{1} \times z^{-1}+\ldots+b_{n b} \times z^{-n b}}{1+a_{1} \times z^{-1}+\ldots+a_{n b} \times z^{-n a}}
$$

Where $n_{a}, n_{b}=2$ and $n_{k}=1$.

Finally,

$$
\begin{aligned}
& \mathrm{G}\left(\mathrm{z}^{-1}\right)=\frac{\mathrm{B}\left(\mathrm{z}^{-1}\right)}{\mathrm{A}\left(\mathrm{z}^{-1}\right)}=\frac{0.19 \mathrm{z}^{-1}-0.19 \mathrm{z}^{-2}}{1-1.78 \mathrm{z}^{-1}+0.78 \mathrm{z}^{-2}} \\
& H\left(z^{-1}\right)=C\left(z^{-1}\right)=1-1.58 z^{-1}+0.61 z^{-2}
\end{aligned}
$$

As shown in Fig. 8, the differences of the estimated and measured data are within $1 \%$.

Note that, the conductive heat transfer is a first order temperature difference. So, the selection of the lower order model is suggested; i.e. $n_{a}=n_{b}=n_{c}=1$. Consequently new model structures are defined.

According to Table 4, Box-Jenkins model matches very well with the measured data and less with state space N4SID model. From the reason that the lower order Box-Jenkins is more accurate than the ARMAX second order model; so we select it as the final transfer function of system. For discontinuous time-invariable single input-output system, the Box-Jenkins model is:

$$
z(k)=\frac{B\left(z^{-1}\right)}{F\left(z^{-1}\right)} u(k)+\frac{C\left(z^{-1}\right)}{D\left(z^{-1}\right)} n(k)
$$

Where,

$$
\begin{aligned}
& B\left(z^{-1}\right)=b_{1} z^{-1} ; F\left(z^{-1}\right)=1+f_{1} z^{-1}+f_{2} z^{-2} ; \\
& C\left(z^{-1}\right)=1+c_{1} z^{-1} ; D\left(z^{-1}\right)=1+d_{1} z^{-1}+d_{2} z^{-2}
\end{aligned}
$$

Combination of Eq. (20), Eq. (21), Eq. (22) and Eq. (27) gives:

$$
G\left(z^{-1}\right)=\frac{B\left(z^{-1}\right)}{F\left(z^{-1}\right)}=\frac{b_{1} \times z^{-1}}{1+f_{1} \times z^{-1}+f_{2} z^{-2}}
$$

The transfer function of the system is:

$$
G\left(z^{-1}\right)=\frac{B\left(z^{-1}\right)}{F\left(z^{-1}\right)}=\frac{0.0067 z^{-1}}{1-1.77 z^{-1}+0.77 z^{-2}}
$$

And the transfer function of disturbance is:

$$
\mathrm{H}\left(\mathrm{z}^{-1}\right)=\frac{\mathrm{C}\left(\mathrm{z}^{-1}\right)}{D\left(\mathrm{z}^{-1}\right)}=\frac{1-0.96 z^{-1}}{1-1.03 z^{-1}+0.027 z^{-2}}
$$

In transient and steady state cases, Eq. (29) is the transfer function of the system and can predict the thermal contact behavior with high accuracy, using the temperature of one end by knowing the other adjacent surface temperature.

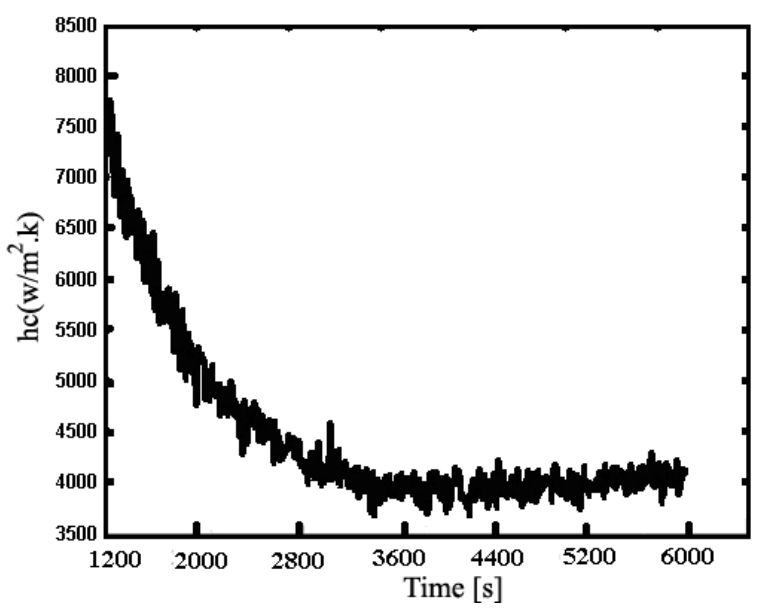

Fig. 7: Heat transfer coefficient at contact surface

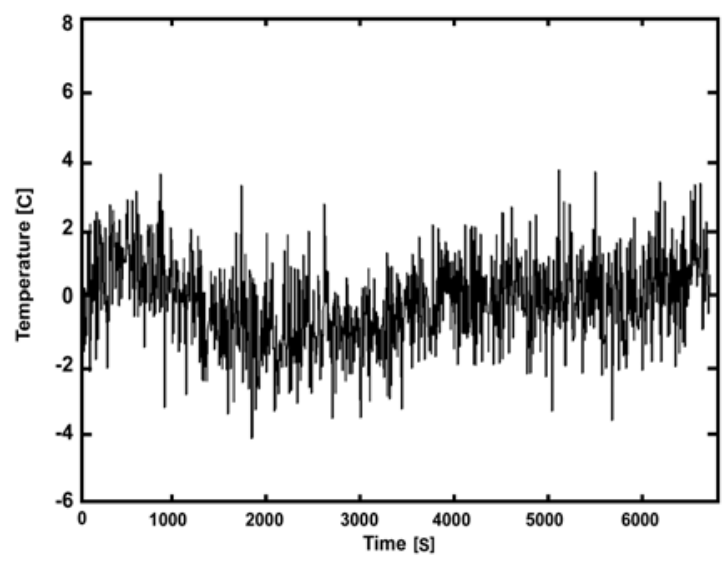

Fig. 8: Residual of the ARMAX model 
The errors due to different sources are discussed in Tables 1-4 and figure 8 . Table 1 indicates the relative measured temperature error at steady state conditions, which is 0.4 percent for the hot rod and 1.0 percent for cold rod. In Table 3 , the relative error and the measured values of the temperature is shown, while Table 4 is for the models of lower order. Figure 8 shows the difference between the measured and estimated temperatures from the ARMAX model that their maximum is 4 centigrade. Figure 7 show the heat transfer coefficient at contact surface

\section{CONCLUSION}

The system identification method is an excellent method to estimate the temperature at contact surfaces with high accuracy. Also, the heat transfer coefficient at the contact surface and the temperature transfer function were calculated. In this method, using the calculated transfer function and knowing the temperature of one rod, the temperature of the other rod was estimated. One of the advantages of this method is that no prior information of the variation of the unknown quantities is needed since the solution automatically determines the functional form over a specified domain. The most common Black-Box parametric model structures are examined. The results of the temperature distribution at the rods were compared with the method of Inverse Cauchy.

This method can be utilized for the estimation of the exhaust valve temperature, which is extremely difficult to measure. By using the calculated transfer function, a computational model can be created. By assigning the exhaust valve seat temperature as input, the exhaust valve temperature can be estimated.

$\begin{array}{ll}\text { Nomenclature } \\ \mathrm{T} & \text { temperature }[\mathrm{C}] \\ \mathrm{x} & \text { distance }[\mathrm{m}] \\ \mathrm{t} & \text { time }[\mathrm{s}] \\ \mathrm{L} & \text { distance between thermocouples }[\mathrm{m}] \\ \mathrm{f} & \text { boundary condition } \\ \mathrm{T}_{\mathrm{inf}} & \text { ambient temperature }[\mathrm{C}] \\ a_{n}(t) & \text { Fourier series coefficients } \\ T_{c 1} & \text { temperature of contacting face on valve }[\mathrm{C}] \\ T_{c 2} & \text { temperature of contacting face on seat }[\mathrm{C}] \\ \mathrm{AD} & \text { analog to digital } \\ \mathrm{Vol} . & \text { voltage [volt] } \\ \mathrm{q} & \left.\text { heat flux [W/m }{ }^{2}\right] \\ \mathrm{K} & \text { thermal conductivity coefficient }[\mathrm{w} / \mathrm{m} . \mathrm{K}] \\ u(t) & \text { input signal }[\mathrm{C}]\end{array}$

$y(t) \quad$ output signal [C]

$G(t) \quad$ continues transfer function

$V(t) \quad$ continues noise term

$q^{-1} \quad$ shift operator [s]

$H(q)$ noise transfer function

$\mathrm{n} \quad$ order of polynomial

$e(t) \quad$ noise structure

$x(t) \quad$ state variable

I identity matrix

$u(k)$ discontinuous input variable

$z(k)$ discontinuous output variable

$n(k)$ discontinuous noise variable

$a_{n} \quad$ coefficient of polynomial A

$b_{n} \quad$ coefficient of polynomial B

$G\left(z^{-1}\right) \quad \mathrm{Z}$ transfer function

$n_{a} \quad$ order of polynomial

$n_{k} \quad$ delay from input to output

$\mathrm{k}$ time delay index

$z^{-1} \quad$ shift operator of $\mathrm{Z}$ transfer function

FPE Final Prediction Error

ARMA Auto Regressive Moving Average

N4SID Numerical Algorithm for Subspace StateSpace System Identification

\section{GREEK SYMBOLS}

$\omega \quad$ frequency variable $[1 / \mathrm{s}]$

$\partial \quad$ partial differential operator

$\alpha \quad$ Thermal diffusion Coefficient $\left[\mathrm{m}^{2} / \mathrm{s}\right]$

$\rho \quad$ density $\left[\mathrm{kg} / \mathrm{m}^{3}\right]$

\section{REFERENCES}

1. Minges, M.L.Jr., 1966. Thermal Contact Resistance. Vol. 1, A review of the literature, Technical Report AFML-TR-65-375, WrightPatterson Air Force Base, Dayton, $\mathrm{OH}$

2. Moore, C. J. C. Jr., Heat Transfer across Surfaces. Ph.D. Thesis, Southern Methodist University, Dallas, TX.

3. Moore, C.J.C. Jr., H. Atkins and H.A. Blum, 1968. Subject Classification Bibliography for Thermal Contact Resistance Studies. ASME Paper No. 68WA/HT-18.

4. Madhusudana, C.V. and L.S. Fletcher, 1981. Thermal contact conductance: A review of recent literature, College of Engineering, Texas A\&M University, College Station, TX. 
5. Thomas, T.R. and S.D. Probert, 1972. Correlations for thermal contact conductance in vacu. J. Heat Transfer, pp: 276-280.

6. Fletcher, L.S. and D.A. Gyorog, 1971. Heat transfer between surfaces in contact and an analytical and experimental study of thermal contact resistance of metallic interfaces, NASACR-114373 ME-TR-033-4, Department of Mechanical Engineering, Arizona State University, Tempe, Arizona.

7. Fenech, H., J.J. Henry and W.M. Rosenhow, 1964. Thermal Contact Conductance, Developments in Heat Transfer, Chapter 13, Edward Arnold, London.

8. Fenech, H., and W.M. Rosenhow, 1963. Prediction of thermal contact conductance of metallic surfaces in contact. J. Heat Transfer, 85: 15-24.

9. Fenech, H. and W.M. Rosenhow, 1959. Thermal conductance of metallic surfaces in contact. USAEC Report, No. NYO-2136.

10. Howard, J.R., 1975. Heat transfer between contacting solids. J. Engineering, pp: 220-222.

11. Paradis, I., J.R. Wagner and E.E. Morotta, 2002. Thermal periodic contact of exhaust valves in spark ignition air-cooled engines. J. Thermophysics and Heat Transfer, 16: 3.
12. Howard, J.R. and A.E. Sutton, 1970. An analogue study of heat transfer through periodically contacting surfaces. Intl. J. Heat and Mass Transfer, 13: 173-183.

13. Reed, J.R. and G. Mullineux, 1973. Quasi-steady state solution of periodically varying phenomena. Intl. J. Heat and Mass Transfer, 16: 2007-2012.

14. Mikhailov, M.D., 1974. Quasi-steady state temperature distribution in finite regions with periodically varying boundary conditions. Intl. J. Heat and Mass Transfer, 17: 1475-1478.

15. Vick, B. and M.N. Ozisik, 1981. Quasi-steady state temperature distribution in periodically contacting finite. J. Heat Transfer, 103: 739-744.

16. Howard, J.R., 1976. An experimental study of heat transfer through periodically contacting surfaces. Intl. J. Heat and Mass Transfer, 19: 367-372.

17. Flach, G.P. and M.N. Ozisik, 1988. Inverse heat conduction problem of periodically contacting surfaces. J. Heat Transfer, 110: 821-829.

18. Moses, W.M. and R.R. Johnson, 1988. Experimental study of the transient heat transfer across periodically contacting surfaces. J. Thermophysics and Heat Transfer, 2: 37-42. 